\title{
Bispectral Index and Other Processed Parameters of Electroencephalogram: an Update
}

(Rev Bras Anestesiol, 2012;62(1):105-117)

In the Brazilian Journal of Anesthesiology, Volume 62, Number 01, where it reads "Suppresion rate is defined as intervals over 0.5 seconds in which EEG voltage is below $\pm 0.5 \mu \mathrm{V}$ (Figure 2). Suppression rate ${ }^{12,13}$ is the epoch fraction (time period of the analysis of two seconds) in which EEG is isoelectric (does not exceed $\pm 0.5 \mu \mathrm{V}$ ).", it should read "Suppresion rate is defined as intervals over 0.5 seconds in which EEG voltage is below $\pm 5 \mu \mathrm{V}$ (Figure 2). Suppression rate ${ }^{12,13}$ is the epoch fraction (time period of the analysis of two seconds) in which EEG is isoelectric (does not exceed $\pm 5 \mu \mathrm{V}$ ).”.

Nunes RR, Chaves IMM, Alencar JCG, Franco SB, Oliveira YGBR, Menezes DGA - Bispectral Index and Other Processed Parameters of Electroencephalogram: an Update. 